\title{
Experimental Set Up of P300 Based Brain Computer Interface Using a Bioamplifier and BCl2000 System for Patients with Spinal Cord Injury
}

\author{
Hyeongseok Jeon, Dong Ah Shin \\ Department of Neurosurgery, Yonsei University Health System, Yonsei University College of Medicine, Seoul, Korea
}

\begin{abstract}
Objective: Brain computer interface $(\mathrm{BCl})$ is one of the most promising technologies for helping people with neurological disorders. Most current $\mathrm{BCl}$ systems are relatively expensive and difficult to set up. Therefore, we developed a P300-based $\mathrm{BCl}$ system with a cheap bioamplifier and open source software. The purpose of this study was to describe the setup process of the system and preliminary experimental results.

Methods: Ten spinal cord-injured patients were recruited. We used a sixteen-channel EEG (KT88-1016, Contec, China) and BCl2000 software (Wadsworth center, NY, USA). Subjects were asked to spell a 5-character word using the P300-based $\mathrm{BCl}$ system with 10 minutes of training. EEG data were acquired during the experiment. After subjects spelled the word for ten trials, the spelling accuracy and information transfer rate (ITR) were obtained in each patients.

Results: All subjects performed the experiment without difficulty. The mean accuracy was $59.4 \pm 22.8 \%$. The spelling accuracy reversely correlated with the age. Younger subjects spelled with higher accuracy than older subjects $(p=0.018)$. However, sex, injury level, time since injury and ASIA scale were not correlated with the accuracy. The mean of ITR was $2.26 \pm 1.22$ bit/min. Conclusion: This study showed that a $\mathrm{BCl}$ system can be set up inexpensively with a low-price bioamplifier and open-source software. The spelling accuracy was moderately achieved with our system. P300-based BCl is useful in young patients, but modification is necessary in old patients who have low ability of recognition and concentration.
\end{abstract}

Key Words: Brain-Computer interfaces $\cdot$ Event-Related potentials $\cdot$ P300 $\cdot$ Spinal cord injuries $\cdot$ Electroencephalography

\section{INTRODUCTION}

Brain computer interface (BCI) is one of the most promising fields in neuroscience. BCI builds direct communication pathway between brains and computer ${ }^{1,10}$. $\mathrm{BCI}$ translates brain signals to command signals for environmental control and communication. BCI is a novel technology for helping people with neurological disorders such as locked-in-syndrome, cerebral infarction, amyotrophic lateral sclerosis, polyneuropathy, cerebral palsy, and spinal cord injury without direct muscular control $^{2,3,7,14,19-21)}$. Whereas other treatment such as stem cell therapy has inevitable safety and ethical issues, BCI circumvents such problems. Thanks to remarkable technological

\footnotetext{
- Received: July 10, 2015 - Revised: August 19, 2015

- Accepted: August 19, 2015

Corresponding Author: Dong Ah Shin, MD, PhD

Department of Neurosurgery, Yonsei University Health System, Yonsei University College of Medicine, 50 Yonsei-ro, Seodaemun-gu, Seoul

03722, Korea

Tel: +82-2-2228-2150, Fax: +82-2-393-9979

E-mail: CISTERN@yuhs.ac

$\otimes$ This is an Open Access article distributed under the terms of the Creative

Commons Attribution Non-Commercial License (http://creativecommons.org/ licenses/by-nc/3.0/) which permits unrestricted non-commercial use, distribution,
} and reproduction in any medium, provided the original work is properly cited. advances in measuring and decoding brain signals, $\mathrm{BCI}$ is now changing a therapeutic paradigm of treating highly disabled patients ${ }^{5}$. BCI captures brain signals from the scalp, dura mater, cortical surface or neurons. Electroencephalography (EEG) is the most commonly used interface, due to its noninvasiveness, fine temporal resolution, ease of use, and low cost ${ }^{11)}$. EEG for BCI control includes sensorimotor rhythm, slow cortical potential, steady state visual evoked potential, and P300 event related potential.

Among them, P300 potential has been widely used for BCI systems". The P300 is evoked in the process of decision making and a kind of event related potential (ERP). The P300 ERP is a positive deflection in the EEG over parietal cortex that is involuntarily generated approximately $300 \mathrm{~ms}$ after a rare but meaningful stimulus among a series of frequently occurring stimuli (oddball stimulus) (Fig. 1). When a person views a significant object, P300 potential occurs at the vertex (Fig. 2) ${ }^{4}$. It is believed to be related with motional intention to catch the significant object. Since the first introduction of P300-based BCI by Farwell and Donchin, it has been developed as a typewriter, electrical switch, wheelchair controller, and neural prosthe$\mathrm{sis}^{6}$. Its simple scheme and relatively strong signal are main advantages for disabled patients.

However, unfortunately, BCI requires a complex multidis- 


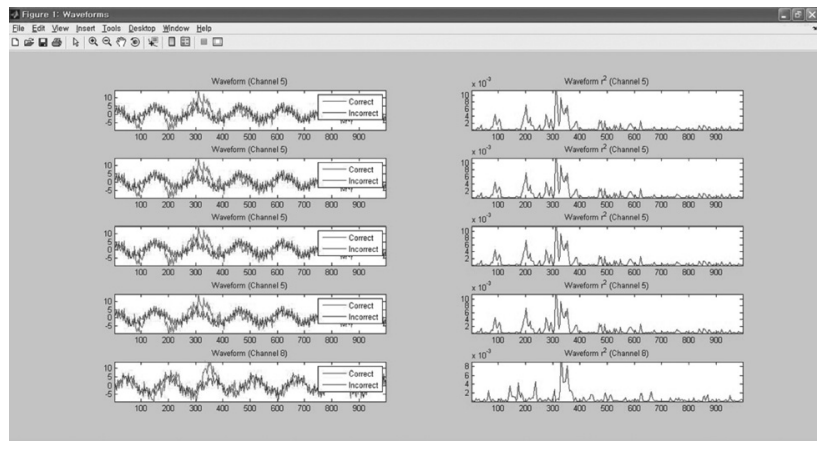

Fig. 1. P300 waveform. Event-related potential which is spiking wave in here is shown around $300 \mathrm{~ms}$.

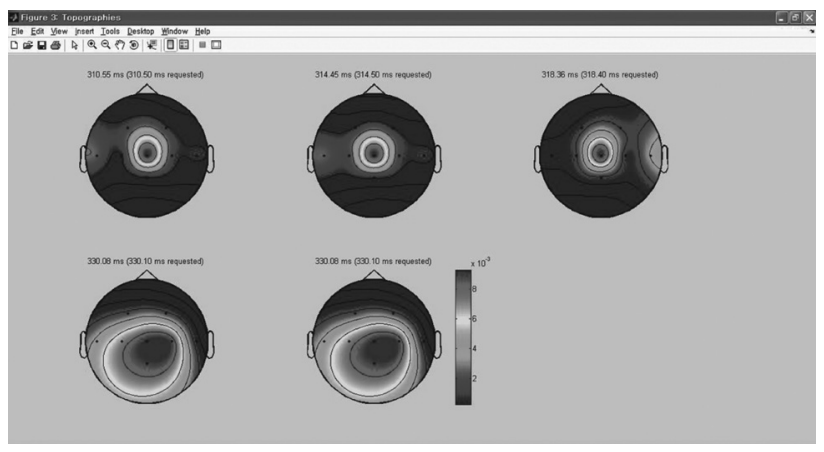

Fig. 2. P300 brain topography. The hot spot around vertex is seen.

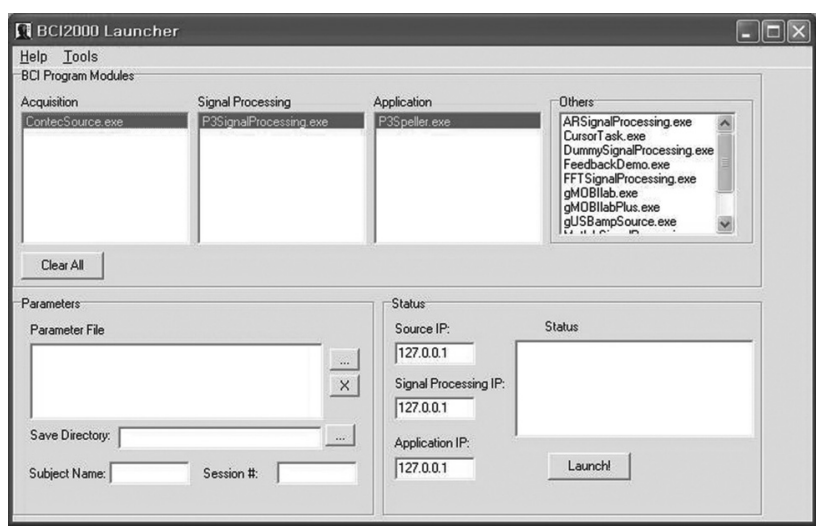

Fig. 3. Basic window of BCl2000 Launcher. This software is opensourced, freely provided by Wadsworth center. BCl2000 supports a variety of data acquisition systems, brain signals, and study paradigms. Window is divided into 3 portions and has an easy interface to be used.

ciplinary endeavor that makes its experimental setup difficult. In addition, most current $\mathrm{BCI}$ systems are expensive. In recognition of this situation, we developed a P300-based BCI system with a cheap bioamplifier and open source software ${ }^{16}$. The purpose of this study was to describe the setup process of the system and preliminary experimental results.

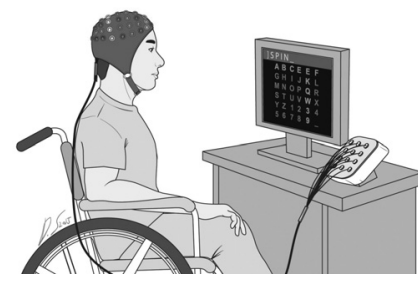

Fig. 4. Experimental set-up. Patient with EEG cap write the word "SPINE" by staring the monitor.

$\begin{array}{cccccc}\text { A } & \text { B } & \text { C } & \text { D } & \text { E } & \text { F } \\ \text { G } & H & \text { I } & \text { J } & K & \text { L } \\ \text { M } & N & \text { O } & \text { P } & \text { Q } & R \\ \text { S } & \text { T } & \text { U } & \text { V } & \text { W } & \text { X } \\ \text { Y } & Z & 1 & 2 & 3 & 4 \\ 5 & 6 & 7 & 8 & 9 & -\end{array}$

Fig. 5. Basic scheme of P300 speller using commercial EEG and $\mathrm{BCl} 2000$ system. $6 \times 6$ matrix consists of alphabets, numbers and space bar.

\section{MATERIALS AND METHODS}

\section{Measurement Set Up}

To implement a P300-based BCI platform, we prepared a sixteen-channel EEG (KT88-1016, Contec, China) for data acquisition. BCI2000 software (Wadsworth Center, NY, USA) and MATLAB 7.1 (Mathworks, MA, USA) were used for data processing. Borland $\mathrm{C}^{++}$Builder 7.0 (Borland, TX, USA) was used to program a bridging module which transports EEG signals from the bioamplifier to the BCI 2000 software (Fig. 3). An EEG cap (ANT, Netherlands) was used to facilitate the accurate placement of electrodes on the scalp. Fig 4 showed the experiment scene.

\section{Performing a P300 Spelling Session}

Ten spinal cord injured patients participated in this study. Subjects tested a P300-based BCI system to spell a 5-character word "SPINE" with 10 minutes of training. EEG data were acquired while the subject looked at a 36-character matrix to spell words. $6 \times 6$ matrix layout which shows better performance than others was used ${ }^{13,17}$. Fig. 5 showed the arrangement of 36-character matrix. The BCI system classifier was trained on the data collected for the words "THE QUICK BROWN FOX".

During the real-time phase of the experiment, the subject spelled the word "SPINE" for ten times, and was provided with the classifier selection accuracy after each of the five letters. We investigated how many letters the subject spelled correctly. And we classified the subject with age, sex, injured spinal cord 
Table 1. Patients' factors and number of corrected letters

\begin{tabular}{|c|c|c|c|c|c|c|c|c|c|c|c|c|c|c|c|}
\hline \multirow{2}{*}{$\begin{array}{l}\text { Patient } \\
\text { number }\end{array}$} & \multirow{2}{*}{ Age } & \multirow{2}{*}{ Sex } & \multirow{2}{*}{$\begin{array}{l}\text { Injured spinal } \\
\text { cord level }\end{array}$} & \multirow{2}{*}{$\begin{array}{l}\text { Time since } \\
\text { injury (year) }\end{array}$} & \multirow{2}{*}{$\begin{array}{l}\text { Severity of } \\
\text { neurology }\end{array}$} & \multicolumn{10}{|c|}{ Session } \\
\hline & & & & & & 1 & 2 & 3 & 4 & 5 & 6 & 7 & 8 & 9 & 10 \\
\hline 1 & 32 & M & $C 4 / 5$ & 7.6 & Complete & 1 & 2 & 2 & 3 & 4 & 3 & 4 & 4 & 5 & 5 \\
\hline 2 & 61 & M & $\mathrm{C} 6 / 7$ & 8.2 & Complete & 0 & 0 & 1 & 1 & 2 & 3 & 2 & 1 & 2 & 3 \\
\hline 3 & 23 & M & $\mathrm{C} 3 / 4$ & 5.1 & Incomplete & 3 & 3 & 4 & 4 & 5 & 5 & 5 & 5 & 5 & 5 \\
\hline 4 & 64 & M & $\mathrm{C} 3 / 4$ & 6.2 & Incomplete & 0 & 0 & 1 & 2 & 0 & 2 & 1 & 1 & 2 & 2 \\
\hline 5 & 46 & M & $C 5 / 6$ & 6.4 & Incomplete & 2 & 3 & 3 & 2 & 3 & 4 & 4 & 4 & 4 & 5 \\
\hline 6 & 34 & M & $\mathrm{C} 6 / 7$ & 4.0 & Complete & 2 & 2 & 2 & 3 & 3 & 4 & 5 & 4 & 5 & 4 \\
\hline 7 & 23 & M & $C 5 / 6$ & 1.3 & Incomplete & 3 & 4 & 4 & 3 & 4 & 3 & 4 & 5 & 5 & 5 \\
\hline 8 & 63 & M & $C 5 / 6$ & 6.9 & Complete & 0 & 0 & 1 & 2 & 1 & 3 & 2 & 1 & 3 & 3 \\
\hline 9 & 55 & M & $C 5 / 6$ & 4.0 & Incomplete & 2 & 3 & 3 & 3 & 4 & 4 & 4 & 4 & 4 & 5 \\
\hline 10 & 42 & M & $C 5 / 6$ & 6.4 & Incomplete & 1 & 3 & 3 & 4 & 3 & 3 & 4 & 4 & 4 & 5 \\
\hline
\end{tabular}

level, the time since injury, severity of neurologic deficit. Severity of neurologic deficit was divided into two groups: complete and incomplete.

We calculated accuracy and information transfer rate (ITR) each patient. ITR had been used as parameters for BCI since Wolpaw et al. ${ }^{22)}$ described in 2000. And we calculated the ITR using formula, $\mathrm{B}=\log _{2} \mathrm{~N}+\mathrm{Plog}_{2} \mathrm{P}+(1-\mathrm{P}) \log _{2}[(1-\mathrm{P}) /(\mathrm{N}-1)]$. $\mathrm{N}$ is possible selections, in case of our study, $\mathrm{N}$ is 36 . $\mathrm{P}$ is probability which is accuracy in our case. We analyzed the relationship between accuracy and age, injured spinal cord level, time since injury using linear regression analysis. For analyzing the relationship between accuracy and complete/ incomplete injury, we used independent t-test. The same method was used for the relationship between ITRs and possible factors. SPSS program (IBM, Chicago, Illinois) was used for analysis.

\section{RESULTS}

All subjects performed the experiment without difficulty. The experimental results of each patient and session were summarized in Table 1. The mean age was $44.3 \pm 16.0$ years old ranging from 23 to 64 . The patients were all male. Four patients were injured above $\mathrm{C} 5$ level. The mean time since injury was 5.6 2.1 years ranging from 1.3 years to 8.2 years. There were 4 complete and 6 incomplete spinal cord injury cases.

The mean accuracy was $59.4 \pm 22.8 \%$ ranging from $22 \%$ to $88 \%$. The results are summarized in Table 2 . Age was reversely correlated with the accuracy $\left(\mathrm{r}^{2}=0.709, \mathrm{p}<0.05\right)$. Standardized regression coefficient was -0.776 . It means that patients with older age showed lower accuracies than patients with young age. Other factors, injured spinal cord level, time since injury and severity of neurologic deficit, showed insignificant difference. The accuracies had increased over repeated sessions $(p<0.05)$. Standardized regression coefficient was 0.972 . The
Table 2. Relationship between accuracies, ITRs and patients' factors

\begin{tabular}{lcc}
\hline \hline Factor & p-value (Accuracy) & $\mathrm{p}$-value (ITR) \\
\hline Age & 0.018 & 0.016 \\
Injured spinal cord level & 0.921 & 0.843 \\
Time since injury & 0.508 & 0.406 \\
Severity of neurologic deficit & 0.216 & 0.262 \\
Over sessions & $<0.001$ & $<0.001$ \\
\hline
\end{tabular}

mean of ITR was $2.26 \pm 1.22$. And like accuracy, age factor was relevant with the accuracy $(\mathrm{p}<0.001)$. Standardized regression coefficient was -0.758 . ITRs over sessions, they had also high tendency. Standardized regression coefficient was 0.986 .

\section{DISCUSSION}

Although BCI was introduced in 1950s, it did not get spotlight until now. The reason for this is that it requires cooperation of multiple fields of science ${ }^{18)}$. For a neurosurgeon, it is difficult to adopt new technologies without previous exposure to it. It requires signal acquisition, data processing, and terminal output. Signals can be obtained in three ways, scalp EEG, subdural electrodes, and intracortical electrodes. Brain waves should be amplified and digitalized for further signal analysis. For specific purposes, variable amplifiers exist and many experts should be involved for making BCI system ${ }^{23}$. However, due to rapid development of information technology, this becomes simpler. EEG amplifiers can be purchased with adequate prices.

Huggins et al. ${ }^{8)}$ reported that people with spinal cord injury have a strong interest in BCIs. For general use, we set up basic BCI development environment using a commercially available cheap EEG and BCI universal platform. We only built one 
software program which transports EEG signals from our amplifier to BCI2000 system. It was very simple to build codes due to well-organized tutorials. Anyone can get information from the website (http://www.bci2000.org). BCI2000 can be used with little change to the software to implement $\mathrm{BCI}$ paradigms. Software engineers can build the platform on the existing modules. It can be configured to disables persons individually. And BCI2000 is an open system that is available free of charge for research and experiment. Experiments were conducted in normal subjects. Spinal cord injured patients usually have normal brain function. So it may be more suitable to spinal cord injury.

In our experiment, patients can easily use the equipment, and accuracy was moderately acceptable. Accuracy of our experiment was about $60 \%$. Ortner et al. ${ }^{15)}$ reported that accuracy of a P300 speller for 15 people with motor impairments including 2 spinal cord injured patients was 70\%. Also, McCane et al. ${ }^{12)}$ reported that the average maximal accuracy for subjects with ALS was 95.7\%. But, this study used maximum accuracy results after repetitive experiments.

EEG-based BCI system has its advantages and disadvantages. Non-invasiveness is most important advantages. Relatively simple paradigm is useful for subject instruction. Therefore, in case of our experiment, all subjects performed the sessions without difficulty and showed fine compliance by non-invasiveness. Despite the training time was short, subjects made moderate accuracy. But in older subjects, the accuracies were relatively lower than younger subjects. It can be important that careful consideration is necessary for use to old-aged patient. Old-aged persons who cannot focus on one thing for a while and do not have high intellectual function cannot perform P300 BCI. Because it requires high mental function and concentration ability, brain-injured patients may not be appropriate candidates. And another possible reason is that scalp EEG is vulnerable to noise conditions. It is simple but may not provide consistent performance.

And, expectedly, there were no differences between two groups; injured spinal cord level, time since injury, severity of neurological deficit ( $p=0.921,0.508,0.216$, respectively). It means we can use our device to various spinal cord injured patients. Also, repetitive sessions were relevant with good results. In our experiment, mean accuracy of first session was only $28 \%$, but in tenth session, that was $84 \%$. It is possible way to improve the low accuracy of our experiment.

However, in case of our study, some limitations existed. Ten subjects are so small. Relatively low accuracy compared with previous reports is a matter of being solved. Old aged person had low accuracy. Education status and awareness of alphabets may affect on result. More acceptable study design could be necessary for these patients. Also, low ITR needs an improvement. Further study must be followed.

Even if that is considered, BCI may be more promising by rapidly developing IT technologies. If we can make more delicate connection to lonely but powerful neurons, many patients with neurological disorders will benefit.

\section{CONCLUSION}

This study showed that a BCI system may be set up inexpensively with a low-price bioamplifier and open-source software. Satisfactory spelling accuracy can be achieved with the P300based BCI system using approximately 10 minutes of training. P300-based BCI is useful in young patients, but modification is necessary in old patients who have low ability of recognition and concentration.

\section{ACKNOWLEDGEMENT}

This study was supported by a grant of the Korea Healthcare technology R\&D project, Ministry for Health \& Welfare Affairs, Republic of Korea (A111016)

\section{REFERENCES}

1. Birbaumer N: Breaking the silence: brain-computer interfaces (BCI) for communication and motor control. Psychophysiology 43:517-532, 2006

2. Birbaumer N, Cohen LG: Brain-computer interfaces: communication and restoration of movement in paralysis. J Physiol 579: 621-636, 2007

3. Birbaumer N, Murguialday AR, Cohen L: Brain-computer interface in paralysis. Curr Opin Neurol 21:634-638, 2008

4. Brunner P, Joshi S, Briskin S, Wolpaw JR, Bischof H, Schalk G: Does the 'P300' speller depend on eye gaze? J Neural Eng 7:056013, 2010

5. Dobkin BH: Brain-computer interface technology as a tool to augment plasticity and outcomes for neurological rehabilitation. J Physiol 579:637-642, 2007

6. Farwell LA, Donchin E: Talking off the top of your head: toward a mental prosthesis utilizing event-related brain potentials. Electroencephalogr Clin Neurophysiol 70:510-523, 1988

7. Huggins JE, Guger C, Allison B, Anderson CW, Batista A, Brouwer AM, et al: Workshops of the Fifth International Brain-Computer Interface Meeting: Defining the Future. Brain Comput Interfaces (Abingdon) 1:27-49, 2014

8. Huggins JE, Moinuddin AA, Chiodo AE, Wren PA: What would brain-computer interface users want: opinions and priorities of potential users with spinal cord injury. Arch Phys Med Rehabil 96:S38-45, 2015

9. Krusienski DJ, Sellers EW, Cabestaing F, Bayoudh S, McFarland DJ, Vaughan TM, et al: A comparison of classification techniques for the P300 Speller. J Neural Eng 3:299-305, 2006 
10. Kubler A, Neumann N: Brain-computer interfaces--the key for the conscious brain locked into a paralyzed body. Prog Brain Res 150:513-525, 2005

11. Machado S, Araujo F, Paes F, Velasques B, Cunha M, Budde $\mathrm{H}$, et al: EEG-based brain-computer interfaces: an overview of basic concepts and clinical applications in neurorehabilitation. Rev Neurosci 21:451-468, 2010

12. McCane LM, Heckman SM, McFarland DJ, Townsend G, Mak JN, Sellers EW, et al: P300-based brain-computer interface (BCI) event-related potentials (ERPs): People with amyotrophic lateral sclerosis (ALS) vs. age-matched controls. Clin Neurophysiol 2015 [Epub ahead of print]

13. Nam CS, Li Y, Jeon Y, Kim Y-J, Yoon H-Y: Usability of the P300 Speller: Towards a More Sustainable Brain-Computer Interface. e-Minds 1:111-125, 2009

14. Nicolas-Alonso LF, Gomez-Gil J: Brain computer interfaces, a review. Sensors (Basel) 12:1211-1279, 2012

15. Ortner R, Aloise F, Pruckl R, Schettini F, Putz V, Scharinger J, et al: Accuracy of a P300 speller for people with motor impairments: a comparison. Clin EEG Neurosci 42:214-218, 2011

16. Schalk G, McFarland DJ, Hinterberger T, Birbaumer N, Wolpaw JR: BCI2000: a general-purpose brain-computer interface (BCI) system. IEEE Trans Biomed Eng 51:1034-1043, 2004
17. Sellers EW, Krusienski DJ, McFarland DJ, Vaughan TM, Wolpaw JR: A P300 event-related potential brain-computer interface (BCI): the effects of matrix size and inter stimulus interval on performance. Biol Psychol 73:242-252, 2006

18. Vaughan TM, Heetderks WJ, Trejo LJ, Rymer WZ, Weinrich $\mathrm{M}$, Moore MM, et al: Brain-computer interface technology: a review of the Second International Meeting. IEEE Trans Neural Syst Rehabil Eng 11:94-109, 2003

19. Vaughan TM, Wolpaw JR: The Third International Meeting on Brain-Computer Interface Technology: making a difference. IEEE Trans Neural Syst Rehabil Eng 14:126-127, 2006

20. Wolpaw JR: Brain-computer interface research comes of age: traditional assumptions meet emerging realities. J Mot Behav 42:351-353, 2010

21. Wolpaw JR: Brain-computer interfaces as new brain output pathways. J Physiol 579:613-619, 2007

22. Wolpaw JR, Birbaumer N, Heetderks WJ, McFarland DJ, Peckham PH, Schalk G, et al: Brain-computer interface technology: a review of the first international meeting. IEEE Trans Rehabil Eng 8:164-173, 2000

23. Wolpaw JR, Birbaumer N, McFarland DJ, Pfurtscheller G, Vaughan TM: Brain-computer interfaces for communication and control. Clin Neurophysiol 113:767-791, 2002 